\title{
Appraisal of Place Identity through Tangible Elements of Cultural Features in Erbil City
}

\author{
Zhino Surchi ${ }^{*}$, Hassina Nafa \\ Faculty of Architecture, Design and Fine Art, Girne American University, Kyrenia, Cyprus
}

Received February 18, 2021; Revised May 20, 2021; Accepted October 20, 2021

\section{Cite This Paper in the following Citation Styles}

(a): [1] Zhino Surchi, Hassina Nafa, "Appraisal of Place Identity through Tangible Elements of Cultural Features in Erbil City," Civil Engineering and Architecture, Vol. 9, No. 7, pp. 2528 - 2541, 2021. DOI: 10.13189/cea.2021.090736.

(b): Zhino Surchi, Hassina Nafa (2021). Appraisal of Place Identity through Tangible Elements of Cultural Features in Erbil City. Civil Engineering and Architecture, 9(7), 2528 - 2541. DOI: 10.13189/cea.2021.090736.

Copyright $@ 2021$ by authors, all rights reserved. Authors agree that this article remains permanently open access under the terms of the Creative Commons Attribution License 4.0 International License

\begin{abstract}
The rapid growth of the cities with transformation of traditional urban spaces has caused a gap between cultural characteristics of urban identities. The identity of a specific place emerges from a series of cultural and social features of the relevant society embodied in the physical forms and shapes of the urban area. The paper aims to attain an overall understanding of keeping urban identity alive throughout the time, by analyzing the cultural characteristics of urban space. The study tries to develop a conceptual model focusing on the tangible relationship between the place identity and the cultural manifestations of the city of Erbil. The study adopted the quantitative way to test whether tangible elements affect place identity. The results indicate that a combination between place identity and cultural places can fortify our experience of place, and understanding of the influence of identity on urban development.
\end{abstract}

Keywords Place Identity, Cultural Landscape Features, Tangible Elements, Erbil Citadel

\section{Introduction}

Cities often experience movement and transition. Universally, changes occur over time and therefore exert a significant effect on community planning and design processes. The revitalization of urban areas is the main goal, yet the overall theory of city identity design is still under debate [1]. Accordingly, investigating identity in the urban areas in creating a tool to assess the form, function, and meaning of the city is vital. Places with a powerful identity help promote awareness and connect within the society [2]. In terms of urban studies, identity is a representation of the distinguishing features of a place or a mixture of inhabitants as a whole [3]. With the concept of place identity (PI), the investigation of the place can be done on what a place seems to be, and what are the common elements that formulate the characteristics of the place. Familiarity with the physical feature of place identity could assist further evaluation of a place's identity [4]. The matter of identity in ancient Kurdish cities for instance Erbil is not a new topic, but it is a new topic in the era of rapid development of the cities in the region. The gap started to be obvious between tradition and modernization conflicts. This study will focus on understanding the relationship between (PI) and cultural features in urban heritage of Erbil. The transformation of historical regions to serve tourism, and the sameness of residential development as well as the consolidation of commercial centers specified the need for awareness of urban identity in urban design [5]. Cultural features will be limited to the cultural-historical landscape which is considered to be the catalyst for economic, environmental, and social development. It has the potential to play a significant role in improving the quality of people life by creating a sense of place for the urban society. Cultural heritage can be divided into two main categories: tangible and intangible. The former (tangible) refers to the structure of the built environment, physical form, and the arrangement of physical objects, while the latter (intangible) refers to activities that occur in the historical places with regards to the traditions as well as the collective memory and sense of the place [6]. The study will emphasize the tangible category, the physical form, and the function of the built environment which are the elements that create the 
identity of the place, in addition to the set of symbols, icons, and values that enrich the place interaction [7]. By interacting and linking the past with the present and the future, the historical-cultural landscape provides a sense of identity and belonging [8]. Hence, in the current study. A quantitative method for the research has been applied, where the form and function are the main concern in accordance with a structured observation as well as content analysis to fulfil this research. This paper tries to explore the tangible or physical aspects in the cultural historical landscapes of Erbil, with a specific focus on Erbil Citadel historical area. The paper attempts to answer the following questions: (i) What are the major quantitative elements to evaluate the identity of a place through the cultural landscape? (ii) How historical cultural features can affect place identity? (iii) To what extent the physical cultural features can assess the urban identity of a place? These questions displayed in the study have been tackled through assessing interactions among physical aspects of the urban identity and physical cultural components to come up with an assessment tool which will be formulated into a model. This model is based on a hierarchy and multi- structural analysis framework, to correlate the physical elements and to evaluate the effects of these elements in assessing identity. The literature has been reviewed and analyzed to describe the main and secondary elements of the (PI). Besides, the correlations of tangible (physical) elements of the (PI) and cultural landscapes have been tested in the model. The case study methodology is also suitable for this research with specific characteristics such as in the Erbil Citadel to be applied to the model in order to test its tangible effects.

\subsection{Urban and Place Identity (PI)}

The appraisal of the urban context value and meaning is the process of the relations among physical objects and material based on people's experience in their daily interaction with the urban area surrounding them. [9]. Since identity relates to the relation between oneself and one's surroundings. Researchers have strived to introduce an objective and comprehensive definition which is, 'the fact of being who or what a person or thing is', [10]. According to Greene [11], visual image of the built environment represents a distinct identity that is bolstered by unique characteristics found in historical and conventional elements of the urban fabric. As a consequence, identity could be referred to in various situations. In one context, identity refers to the number of people who inhabited an urban area, plus the physical attributes in that urban area, in addition to the tangible and intangible heritage and cultural cohesion [12]. Devine-Wright [13], addressed that urban identity is recognized by preserving the cultural traditions which are valuable to people, communities and cities while implementing urban development. Inhabitants who are connected to urban areas and enrich their reality based on daily activities are the ones who understand urban form. This is particularly evident in traditional neighborhoods, where residents have a strong sense of identity and are committed to maintaining community values, beliefs, and traditions [14]. Urban identity can be viewed in the unique property that a city or place has outlined throughout its history, present, and future [15]. Urban identity has been classified by urban theorists into three features: 1) Physical features (static), which shape the physical environment and the materialist fabric of the structure and opened places of a building; 2) Features of activities (Dynamic), which refer to the mutual interaction among people and the way that they use the physical fabric; and 3) Meanings features (perceptual), which are connected to human-being conducts, behaviors, and expertise and include the signs, and symbols [8]. See figure 1 .

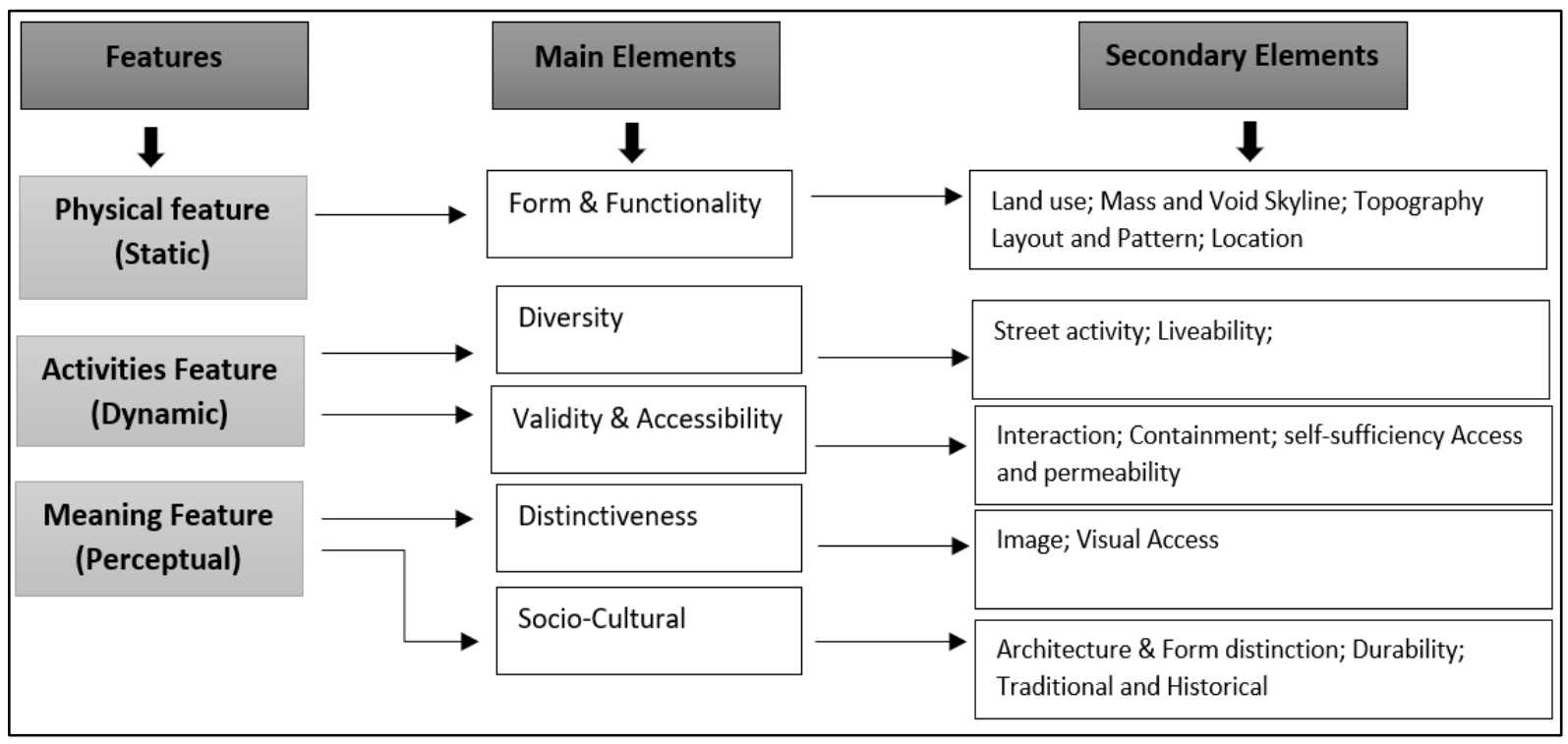

Figure 1. The elements of Urban Identity from [4], (By Researcher) 
There are many factors and elements that researchers have identified to assess (PI) in urban areas. In this sense, a comprehensive outline of the basic parameters for measuring urban identity can be formulated from the review of the literature to be suggested for further urban studies. As mentioned previously, with respect to figure ' 1 ', the study focuses on the physical elements in the methodology as a quantitative method. The notion of place identity symbolizes the connection of the physical environment with its conceptual and functional dimensions. Lynch [16] confirmed that the place identity could be measured and observed by describing or testing of recognition, and recall. Social identity theory, place identity theory, and identity processes theory are the main theories used to describe the impact of architecture as the built environment, natural environment, as well as the identity of a person on each other in the field of environmental psychology [17]. Stokols and Shumaker [18] defined place as the entity that bridges the gap between senses, physical characteristics, and proportional activities.

Commonly, places and identity are related to each other by two ways: place identification, and place identity. The former place identification refers to individuals who expressed their identification with a place, alike Californian's people may consider themselves from California. Accordingly, places can have the same rules as a social identification in terms of social identity theory [19]. The latter 'Place identity' means the connection between place and identity. According to Proshansky (1978), as cited in Twigger and Uzzell [19], 'Place identity' is another shape of identity that can be compared to social identity to show the individual's familiarization with the physical sphere. Breakwell [20] proposes a model that involves four principles of identity. These principles are counted as distinctiveness, continuity, self-efficacy, and self-esteem, and each of which are explained as follows: 1 ) Distinctiveness: The individual uses place identification to distinguish oneself from others; 2) Continuity: the place offers a sense of self-continuity in situations where a person has lived at a certain location for a long time, or where a person chooses the same sort of places to live as before; 3) Self-esteem: It refers to the pride of people because they belong to a specific place that they live in; and 4) Self- efficacy: It refers to the distinctiveness of the place in offering special facilities for people's daily.

The essentials of identity must be formed in an environmental status instead of a socio-psychological condition [19]. However, according to Kermani and Alalhhesabi [21], distinctiveness includes the visual perception of the spectacle by humans, which are physical, functional, and perceptual. Based on the literature, figure ' 2 ' demonstrates the relationships between physical aspects (tangible), and the meaning aspects (intangible) of the place. These aspects have been divided and detailed through their main characteristics (physical and perceptual). The perceptual characteristic includes 'self-esteem and continuity' elements, while the physical characteristics consist of elements of 'distinctiveness and self-efficacy', which are the functional and physical elements.

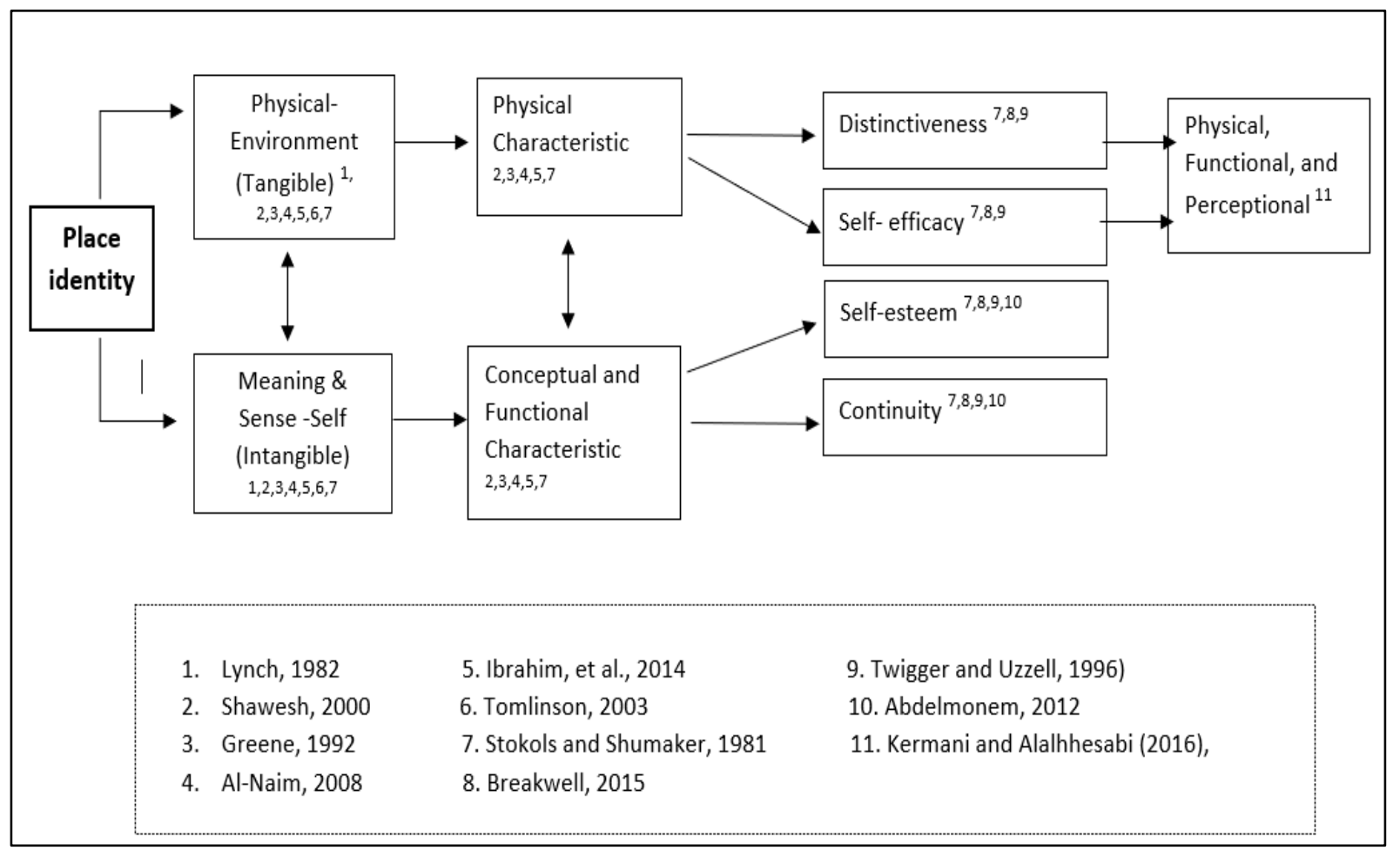

Figure 2. Place identity aspects connections and principles. (By researcher) 


\subsection{Cultural Landscape (CL)}

UNESCO World Heritage Center [22] introduced a term to define cultural landscapes (CL) as assets that reflect the combination of natural and human works. [23] provided a simple description of cultural landscape by means of "a cultural group's creation of a natural landscape" where mainly, culture is the catalyst, the environment is the median, and (CL) is the consequence. Afterward, Cosgrove [24], suggested that (CL) considers a harmony of aesthetic value and social factors between place and individual life, and it is therefore a way to see the world based on aesthetic assessment. Cosgrove [24] claimed that aesthetic value is expressed by cultural constructs and the use of land by people. Jones [25] has stated that the term "cultural landscape" has been traditionally used to define the act of humans in altering the land surface. He also emphasized the importance of effect of human-being and his efforts to enhance the term (CL). Accordingly, as a basis for explaining cultural landscape, there are relationships between environment, community, and people. In this sense, cultural landscape describes the communities of the settlements of inhabitants with the time, as a result of physical restrictions and opportunities presented by the natural surroundings and sequentially cultural, financial, and social powers [7]. Cultural landscape research often contrasts available strategies for sustainable land use, taking into account the characteristics and constraints of the natural environment in which they are situated, and the inherent relationships between man-made structures and nature [22]. As a result, cultural landscape is a dynamic structure of human-induced environmental changes. It is crucial to understand which characteristics can form the cultural landscape of a place.

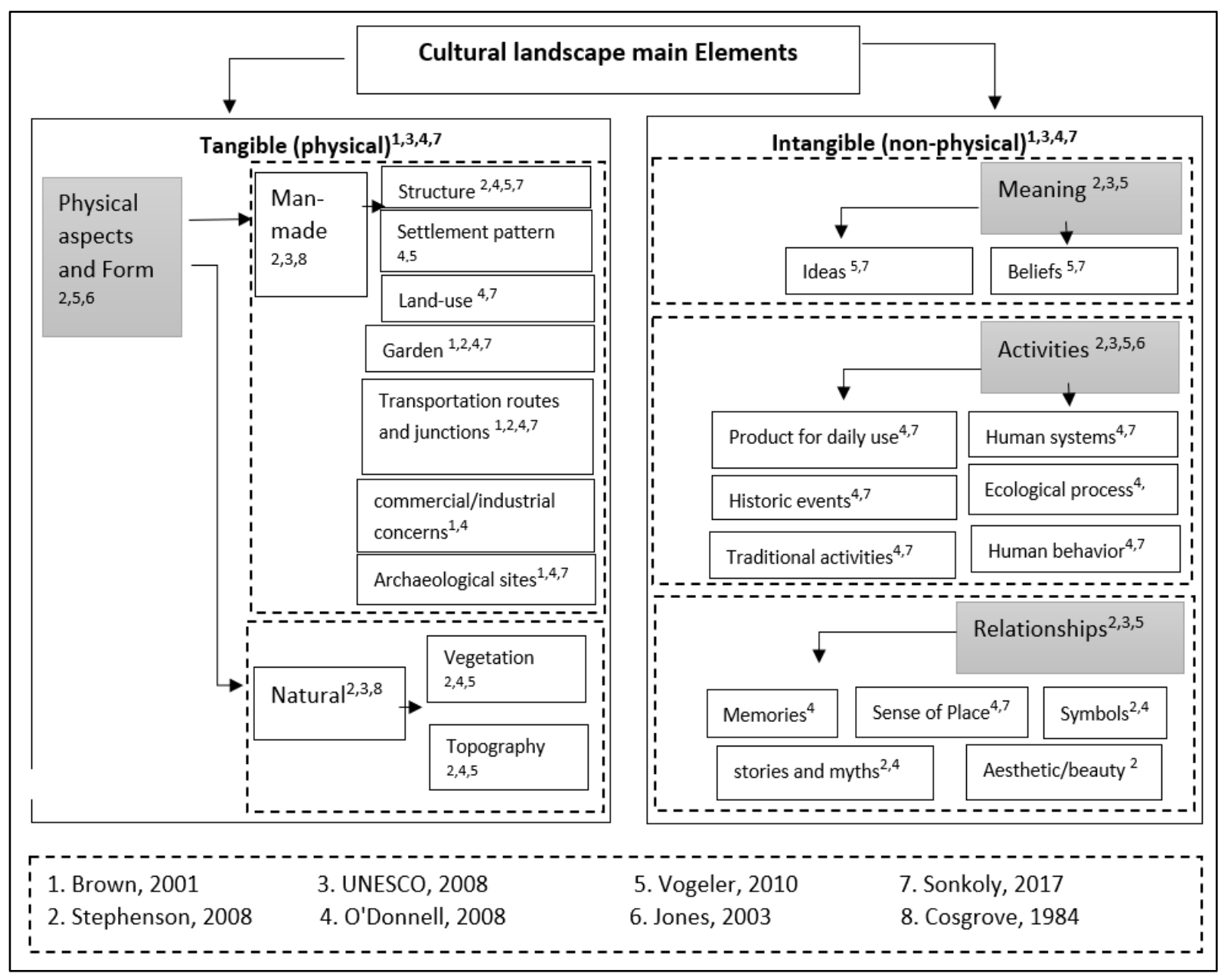

Figure 3. Tangible and intangible elements of the cultural landscape assessment (By Researcher) 
Many scholars categorize elements of the cultural landscape into physical (tangible) and non-physical (intangible) features on a regular basis. O'Donnell [26], asserted that the cultural landscape is divided into two categories: 'tangible', which relates to the material sides of the landscape as natural systems, patterns, land uses, etc., and 'intangible', which refers to the essence of the land or place. Moreover, Brown [27], introduced an analogue rating of (CL) elements as tangible (Intersections and junctions, cover of the land, cultural places) and intangible, like, census and political or ownership borders). However, Vogeler [28], classified the features of CL to three primary sections introduced through (i) meaning, (ii) activities, or the behavior of people(iii) substantial or physical forms, which include, vegetation, settlement patterns, topography, etc. Then according to Stephenson [29], cultural landscape characteristics can be categorized into three categories: (i) forms, which refer to physical and tangible elements, and includes natural forms as vegetation, and human activities as structure and buildings; (ii) relationships, which are related to perception, thought, and symbol; and (iii) activities, which refer to the process. Sonkoly [30], has determined the tangible and intangible elements of (CL) which are distinguished by the living and constructed forms of culture. Built culture refers to the visual aspects of the living place in the society, while living culture includes the human life perception through beliefs and ideologies by their behaviors. Analysis of the properties of developing urban places with their materialist and cultural contexts can offer sensible imaginations and evaluation for the cultural landscape in recent era [31]. The following figure 3 lists some of the main elements that can be used for the study of (CL) in urban areas.

\section{Methodology}

The place identity in relation to the urban cultural landscape is evaluated through the development of a conceptual model connecting tangible elements of the cultural landscape of Erbil with the physical indicators of the identity of the place. The importance in the relation between cultural aspect and place identity is that the process of identifying cultural areas rather than just authenticity or historical dimension may inherit the realm of place identity. Therefore, the identity through cultural aspects is significant.

Thus, in the theoretical part, the paper briefly considers the concept of identity of the place, cultural landscape indicators, and the effects of cultural features on place identity with an analytical method. The researcher draws on literature to formulate the initial factors to build up the main elements of place identity as well as its cultural features. This paper tries to highlight the cultural landscape as an influential aspect of the urban identity, through a field study, and to come out with theoretical models to interpret the relationship between cultural landscape and place identity. As mentioned in the introduction, the study focuses on the tangible category, the physical form and function of the built environment as the initial aspect of the identity of the place. In the practical part, the first stage includes selecting the city of Erbil as a case study to be analyzed based on the proposed model. The analysis concerns the effects of main cultural tangible components of Erbil through its Citadel as the main cultural-historical landscape in the city on the place identity. Secondly, based on the results obtained from the first stage, the study develops a matrix list to try to understand the influence of Erbil Citadel as a cultural landscape on the identity of Erbil.

\subsection{Proposed Model}

The culture notion has a wide range that creates difficulties in overcoming all linked sides through the diversity of urban layers [32]. Consequently, it is important to have a more objective tool for evaluating the cultural characteristics of the place through time. The study was based on the main influential tangible elements as seen in figure 3 , to formulate the proposed model which can establish the relationship between place identity and the cultural landscape. This model was adopted through descriptive and analytical methods based on the literature review, focusing on both concepts of identity and culture. The proposed model reveals that a connection has been found among the main elements of the cultural landscape (natural and man-made) and place identity (physical form and function) in terms of physical aspects or tangible values. The connection has covered the secondary elements of these main elements, which include the effects of cultural landscape secondary elements (structure, settlement patterns, land use, transportation routes, commercial and industrial concerns, archeological sites, natural vegetation, and natural topography) on physical aspects of place identity. The place identity included the form and function as main elements, and the secondary elements include land-use, patterns and layout, and self-efficacy, as shown below in figure 4. Nevertheless, beyond the theoretical review discussed above in regard to tangible and intangible aspects of the landscape, evidence needs have been assessed focusing on tangible aspect in both concepts of identity and culture to establish the relationship between place identity and cultural landscape. 


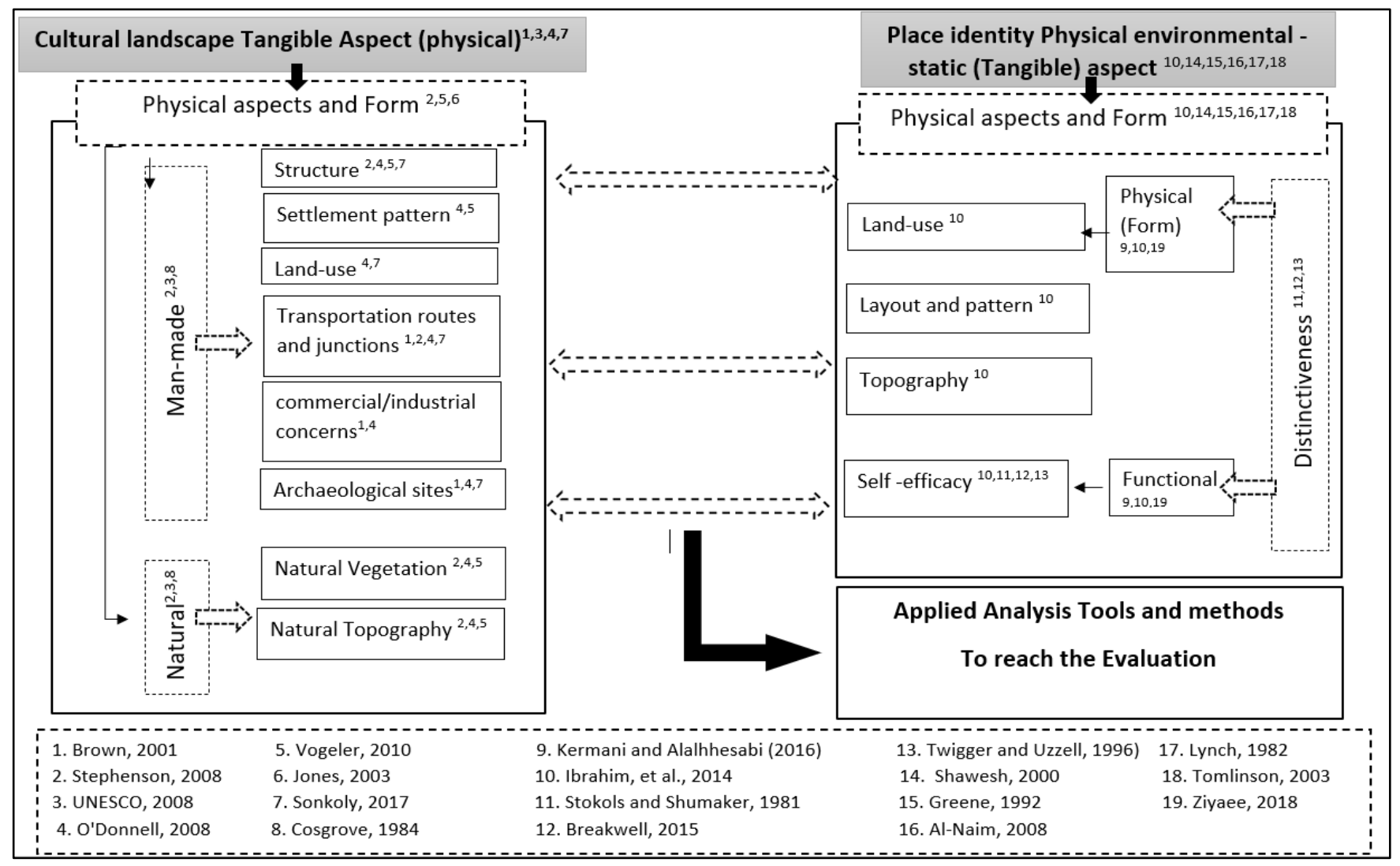

Figure 4. The proposed model for the relationship between Place identity and Cultural Landscape (By Researcher)

Table 1. Matrix checklist to assess cultural landscape relationship with identity of place. (By researcher)

\begin{tabular}{|c|c|c|c|c|c|c|c|c|}
\hline \multirow{2}{*}{ Identity elements } & \multicolumn{6}{|c|}{ Man-made main elements } & \multicolumn{2}{|c|}{ Natural main elements } \\
\hline & Structure & $\begin{array}{c}\begin{array}{c}\text { Settlement } \\
\text { patterns }\end{array} \\
\end{array}$ & Land-use & $\begin{array}{c}\text { Transportation } \\
\text { routes and junctions }\end{array}$ & $\begin{array}{c}\text { Commercial/ } \\
\text { Industrial concerns }\end{array}$ & $\begin{array}{c}\text { Archeological } \\
\text { sites }\end{array}$ & Natural Vegetation & Natural Topography \\
\hline Land use & X 1-1 & X 2-1 & X 3-1 & X $4-1$ & X 5-1 & X 6-1 & X 7-1 & X 8-1 \\
\hline Layout and patterns & X $1-2$ & X $2-2$ & X 3-2 & $\mathrm{X} 4-2$ & X 5-2 & X 6-2 & X 7-2 & X 8-2 \\
\hline Topography & X 1-3 & X 2-3 & X 3-3 & $X 4-3$ & X 5-3 & X 6-3 & X 7-3 & X 8-3 \\
\hline Self-efficacy & X 1-4 & X 2-4 & X 3-4 & X 4-4 & X 5-4 & X 6-4 & X 7-4 & X 8-4 \\
\hline
\end{tabular}


Furthermore, the relations among the mentioned secondary elements and components of place identity and cultural landscape are organized in a matrix checklist to reveal the connections.

Each of the culture specific elements will be weighted based on their contributions in shaping the identity of the place according to the analytical basis. The strength of the cultural landscape components (secondary elements) will be evaluated on the basis of the influence on the largest number of identity elements. For example, the place identity element (Topography) could be influenced by one or more than one element of cultural landscape elements.
The connections will be based on site observation, image interpretation, and maps analysis. As an example, the diversity in natural green cover types in the specific regions creates a natural identity for the place as it is coded by ( $\mathrm{X}$ $7-3)$, as seen in table 1 . These connections will be evaluated based on their contributions. and could be divided into two types: (1) representing the contribution of the element, and (0) the neutral or non-contribution of the element. Therefore, the connections among the cultural elements and place identity elements will be explained based on the descriptive analysis supported by the created matrix checklist codes.

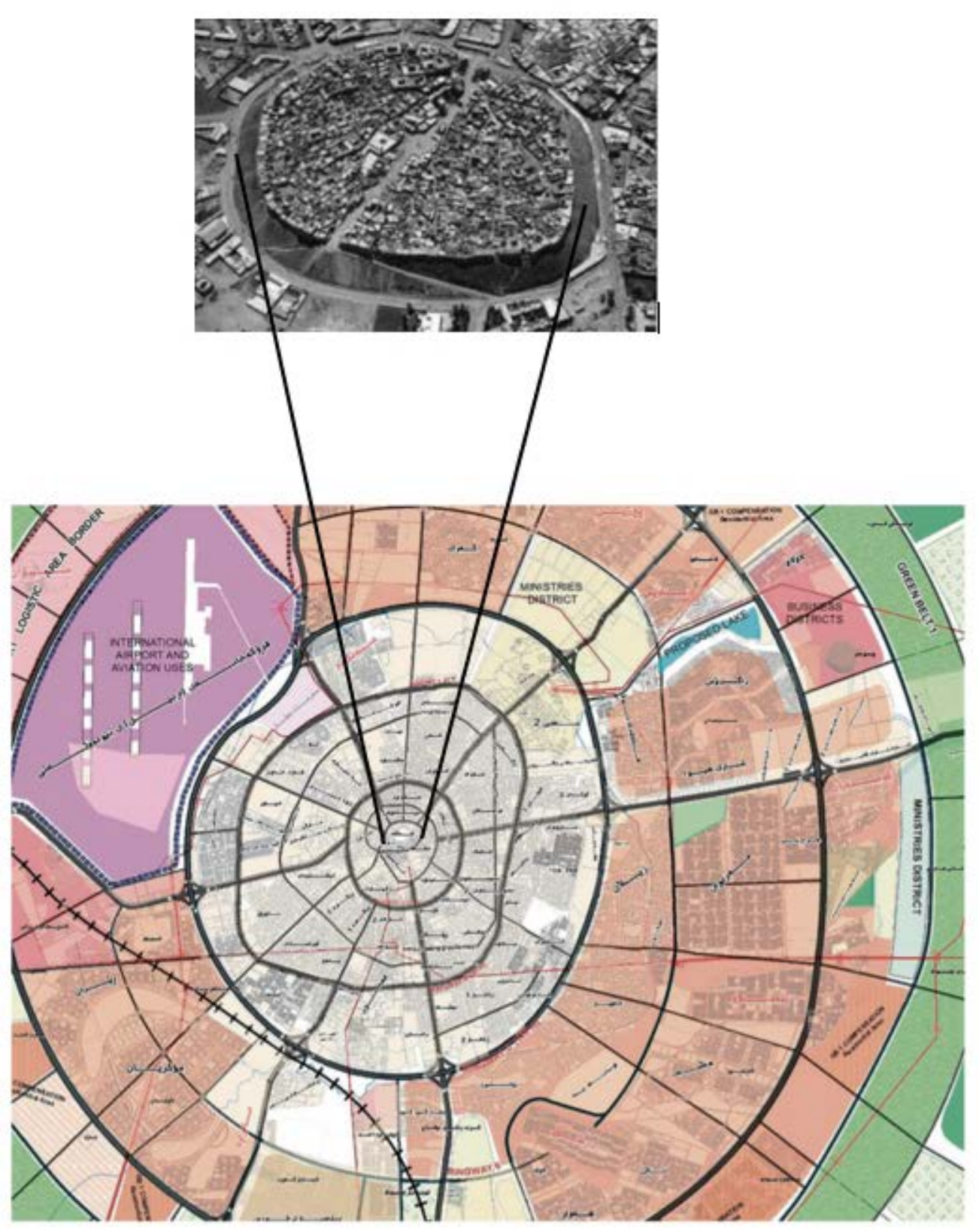

Figure 5. The citadel of Erbil within the master plan of the city, from [37] 


\subsection{Case Study Description}

The assessment of the effect on the Erbil place identity necessitates providing the necessary information of the milieu and especially on the Citadel (Qala). This is achieved through collecting evidence in terms of the location, texture, cultural characteristics of the place based on the tangible levels. Erbil is one of the world's oldest continuously populated city, which goes back to almost 6000 years [33]. The city is the capital of the Kurdistan region of Iraq (Northern Iraq) Amin and Muhy Aldin, [34], situated 345 kilometers north of Baghdad the capital of Iraq. About $80 \%$ of the total population in this region lives in cities and towns, and only 20\% lives in rural areas [8]. Before the modern period, most Kurdish cities in northern Iraq displayed unique architecture and urban contexts that retained their traditional characteristics and local features [35]. The Qala which is Erbil Citadel is a historical and cultural landscape, and located in the center of Erbil city. It consists of the historical core topped on a circular mound of 30 meters high, covering an area of almost 150,000 $\mathrm{m}^{2}$ and embankments slopes in between $35^{\circ}$ and $45^{\circ}$, as shown in figure '(6-c)', [36]. This archeological artificial hill is the result of the accumulation of historical remains, and the elevation considers an archeological wealth. The citadel on the top of this elevation consists of housing 322 groups of buildings, many palaces, baths, and four mosques dated from the eighteenth century and still in the present days [36]. The citadel of Erbil has significantly affected the development of the shape of Erbil city first through the traditional neighborhoods surrounding the citadel and then by a much-modernized extension when distancing from the center core. The preservation of the city core has engendered a circular expansion beyond the citadel which is influenced by the existing physical layout (figure 5).

\section{Analyses and Findings}

It should be mentioned that the studied cultural landscape of Erbil's citadel acts as a core that has shaped the recent city and the oldest part of it. Then, through the proposed model the assessment has been performed with the support of analysis of the developed matrix table, where the connection among cultural landscape elements and place identity elements have been analyzed. In the following sections (I. land use, II. Layout and Patterns, III.
Topography, and IV. self-efficacy, the study summarizes data collected by performed site observation, picture interpretations, and then descriptive analysis of the connections and contributions of the elements in the selected case study. The following secondary elements of place identity, namely land-use, layout and patterns, topography, and self-efficacy, will be tested by the effect of cultural landscape components as seen in table 2 .

\section{Land use}

The structural element which refers to the structure of the Citadel of Erbil as one of the man-made elements in cultural landscape elements influences strongly the land use in place identity. This is through the distribution of the most commercial buildings, especially traditional retail, around the Citadel, and the existence of tourist places like gardens, café, and restaurants near this place. The settlement patterns as the other secondary element of cultural landscape refers to the human activities across the landscape. The Citadel has an important role in driving the morphology and the activities in the region, where the more crowded areas in the city of Erbil is around the citadel, therefore this element is considered as a contributor. Moreover, the cultural land-use of the citadel is considered as a permanent historical area, as also one of the preserved areas by UNESCO since 2007. This nomination has certainly highlighted the identity of the place endlessly, thus the cultural land use contributor. In place of the Citadel (Qala) on an elevated location, the accessibility routes are very limited, consequently it is abandoned and lacks commercial and industrial activities. Therefore, transportation routes, and commercial/industrial concerns stand both as non-contributors and being also secondary elements of the cultural landscape. The Archeological characteristic of the cultural landscape affects land use elements in the identity of Erbil strongly. It should be mentioned that the most touristic and commercial activities as well as recreation areas like parks and gardens were created near the citadel area because of its historical value, as seen in figure 6- (b\&d).

The fact that there has not been any recognition of a natural vegetation and topography for the elevated position of the citadel, the non-natural man-made topography is a result of an accumulation of historical remains [36]. In this sense, both natural vegetation and natural topography were assessed as non- contributed elements. 


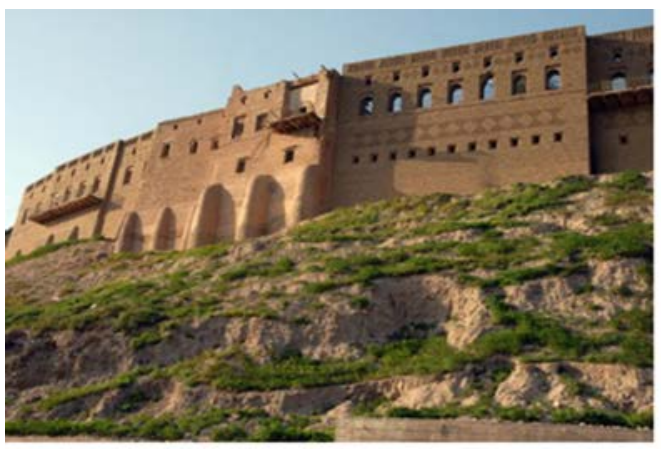

(a)

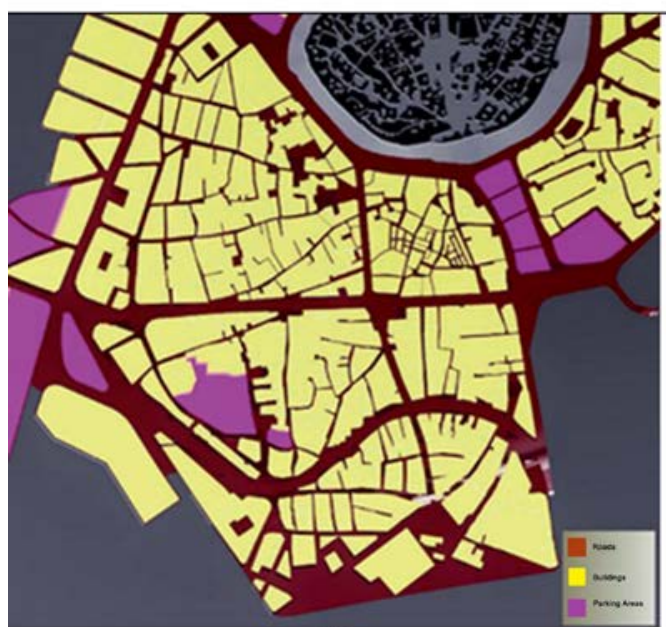

(b)

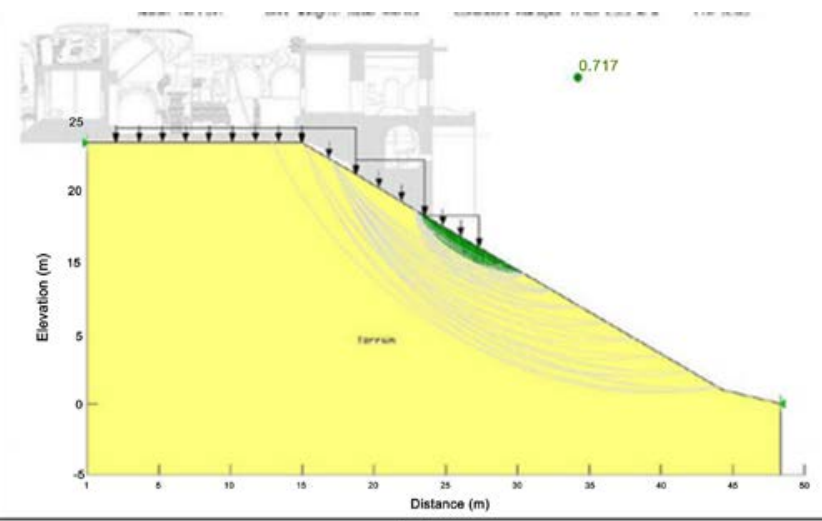

(c)

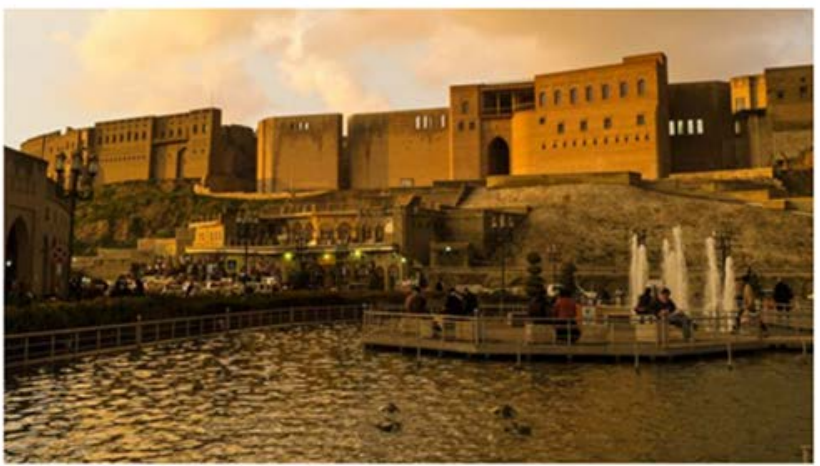

(d)

Figure 6. (a), The massive structure of Citadel from outside (By Author); (b) land use and settlement patterns around the citadel, red is the roads, yellow is the buildings, and light violet is the parking areas [18]; (c) section shows the elevation of the citadel from surrounding area [20]; (d) shows the parking and recreation area around the citadel, (By researcher).

\section{Layout and Patterns}

The spatially mixed distribution of the settlement patterns within the Citadel are the main concerns in this study. There is a clear distinction between settlement patterns as one furthers away from the core of the Citadel. The Arab district as the closest one shows a complex and dense layout whereas the Zanko district as the farther displays a great change of layout distribution. See figure 7 .

Accordingly, the secondary elements of the cultural landscape of the settlement patterns have contributed to placing identity regarding its Layout and patterns elements. The mixed-in layout patterns near the Citadel create variety in land use as explained earlier. The complexity in the patterns near the citadel is affected by the presence of the citadel as the destination of the people and as the center of the city of Erbil. Hence, the cultural landscape 'land use' around the citadel has been considered contributory element because it gave a special pattern and layout to the place through different activities and functions by commercial, residential, touristic activities. 'Transportation routes and junctions', as another cultural secondary element, affected the layout patterns of the city's identity. Where the basic 'Quasi-circular' basic shape of the Citadel border has led all the transportation routes in the city to become circular and look like rings with the same center of the Citadel. As mentioned previously, the commercial and industrial activities inside the Citadel does not exist, and consequently, it will not affect the layout pattern directly. The relationship between the Citadel and the surrounding parts got an especial spatial relationship due to the elevation of the citadel above regular surrounding lands by almost 30 meters because of the archeological accumulations in the place. Accordingly, this secondary element of 'Archeological sites' considers as effective on the layout and pattern of the city. Again, natural vegetation and topography are not involved in the citadel elements and will not be considered as contributors. See table 2. 


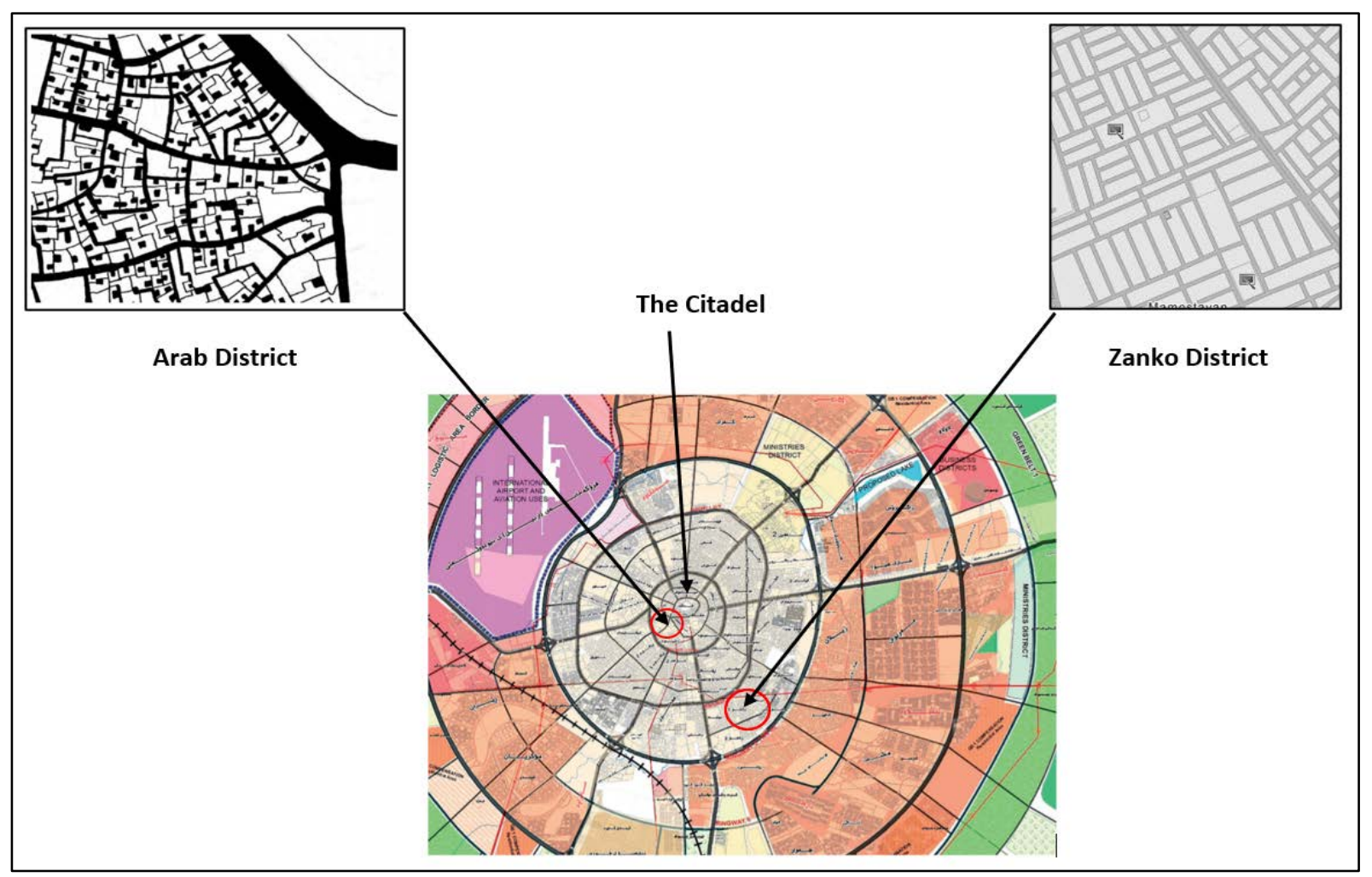

Figure 7. Layout patterns in (Arab district- close to the citadel) \& (Zanko district- far from the citadel), (By researcher)

\section{Topography}

Because of the positioning of the Citadel as a mass structure higher than the flat land of the city of Erbil, this issue made an overall view of the citadel as a distinct place. Accordingly, the secondary element of cultural landscape 'structure' has affected the identity of the place through the topography. The building patterns around the elevated citadel with the lower level follow the regular order of the citadel border. Therefore, 'settlement patterns' can be considered as an effective cultural element on the identity of Erbil. 'Land use, transportation routes, and commercial/ industrial, were secondary elements without a direct effect on the topography of the place identity, because of the regular characteristic of the topography in Erbil city. However, the positioning of the Citadel is strongly affected by the 'archaeological site' as a cultural landscape secondary element, which allowed the Citadel to be distinguished and higher than surrounding flat land, and therefore, the 'archaeological site' has considered a contributor. Moreover, the shortage of 'natural vegetation' makes this element be non-contributory to the identity of the place through topography. The same is true for the natural topography of the Citadel, because the elevation of the Citadel is artificial or man-made, and it is not natural.

\section{Self-efficacy}

This element concerns with the functional elements of the physical aspects of place identity. It refers to the distinguishing characteristic of the place in presenting special facilities for the people on a daily basis. The citadel itself does not offer any special function to the people in terms of its structure, because it is an abandoned area. This means that the 'structure' as a secondary element of cultural landscape has not contributed to the identity through 'self-efficacy' element. The same reason is valid for the other cultural secondary elements 'transportation routes and junctions, and Land-use'. Moreover, 'Commercial /industrial concerns' is another secondary element of culture that has no contribution to the self-efficacy due to the missing of these activities inside the Citadel. However, 'settlement pattern' element has effects on the 'self-efficacy', through the difficulties in reaching the citadel because of the difference in elevation which impacts self-efficacy negatively. 'Archaeological site' secondary elements of cultural landscape have a positive effect on the 'self-efficacy' of the identity of the place, through the advantages of this place as a historical landmark, which make it a destination inside the city. Because the Citadel is a man-made cultural landscape, both natural elements (natural vegetation, and natural topography) are not contributed. The total evaluations for the effects of cultural-historical landscape (Erbil's citadel) on the identity of Erbil are indicated empirically in table 2, according to the previous description and analysis. 
Table 2. Evaluation of Erbil's Citadel as a case study on the identity of place in Erbil city (By researcher)

\begin{tabular}{|c|c|c|c|c|c|c|c|c|}
\hline \multirow[b]{3}{*}{ Identity elements } & \multicolumn{6}{|c|}{ Man-made main elements } & \multicolumn{2}{|c|}{ Natural main elements } \\
\hline & Structure & $\begin{array}{c}\text { Settlement } \\
\text { patterns }\end{array}$ & Land-use & $\begin{array}{c}\text { Transportation routes and } \\
\text { junctions }\end{array}$ & $\begin{array}{c}\text { Commerc. } \\
\text { /Indust. concerns } \\
\end{array}$ & $\begin{array}{c}\text { Archeological } \\
\text { sites }\end{array}$ & $\begin{array}{c}\text { Natural } \\
\text { Vegetation }\end{array}$ & $\begin{array}{c}\text { Natural } \\
\text { Topography }\end{array}$ \\
\hline & & & & & & & & \\
\hline Land use & 1 & 1 & 1 & 0 & 0 & 1 & 0 & 0 \\
\hline Layout and patterns & 1 & 1 & 1 & 1 & 0 & 1 & 0 & 0 \\
\hline Topography & 1 & 1 & 0 & 0 & 0 & 1 & 0 & 0 \\
\hline Self-efficacy & 0 & $1^{*}$ & 0 & 0 & 0 & 1 & 0 & 0 \\
\hline
\end{tabular}

*refers to the negative impact during the connection 
These intercourses have been evaluated based on their contributions and were divided into two types: (1) is considered for the contribution of the element, either positively or negatively, while (0) is for the neutral or non-contribution of the element. Based on the proposed strategy of evaluation through the matrix checklist (table 2), the results demonstrate that the Citadel does not have the natural characteristics. Hence, the natural secondary elements of the cultural landscape (natural vegetation, and natural topography) were non-contributing. Therefore, they scored (0), during the connection with all the elements of place identity. However, it should be mentioned that the most effective elements of the cultural landscape were 'Archeological sites' and 'Settlement patterns'. The reason goes back to the historical character of Erbil's citadel, and its significance in the urban texture as the core of the Erbil master plan. The second influential secondary element of culture on place identity was the 'structure', which is also because of the historical character of the citadel with the shape of the building and urban form. The 'Land use' secondary element of culture has moderate influence on the identity through its effects on identity in terms of place identity 'land use, and layout and patterns'. The abandoned citadel made the impact of 'transportation routes and junctions, and the commercial/ industrial' elements very weak on the place identity. Therefore, it is an alarm to the planner and the developers to pay attention to this point and try to revive the place through specific strategies. It should be mentioned that in terms of functional identity which is presented in this study by the element 'Self-efficacy', only two elements of culture were contributing to it, namely, 'Archeological site and settlement patterns'. 'Archeological site' element had a positive impact on functional identity, through the advantages of its historical value, which convert the place to a destination for the visitors, and the center of the city in the master plan of Erbil city. However, 'settlement pattern' which is measuring the human activities across the citadel has a negative impact on the identity due to the difficulties in reaching the citadel because of the difference in elevation. In addition to this, the difficult accessibility into the citadel causes the weakness in functions inside the citadel because of the low access to the inside area. Hence, the absence of functions and activities inside the citadel of Erbil made the functional element of identity weaker. This has been found in the connection between self-efficacy and settlement pattern in the second column in table 2.

\section{Results, Conclusion and Recommendation}

The study proposed a model (Fig.4) of the relationship between identity and culture in terms of physical aspects (tangible). The physical form and function create the identity of the place, then other sets like symbols, icons, and values will be added to enrich the place. The literature review has been approached to describe the main aspects and elements of the place identity and the cultural-historical landscapes. The model has applied to the major elements of the cultural landscape, which are man-made and natural with the major aspects of the identity of the place which are form and function. Erbil Citadel as a cultural-historical landscape has been tested to understand its influence on the identity of Erbil city. The matrix checklist has been conducted as an assessment tool for evaluating the results empirically. The case study analysis has demonstrated that the identity (Physical) of the citadel can be considered as a central confined area followed by the extension parts respecting the circular boundary of the citadel area. The findings from analyzing the matrix checklist are as follows. On the basis of the form aspects, the citadel is now influenced by the cultural man-made element and has not been influenced by the natural elements. However, the most effective features in the man-made element were the secondary elements, 'archaeological sites, settlement patterns, and the structure' secondary elements were lower than them, which is followed by 'land use'. The lowest effect of cultural secondary elements on identity was 'transportation routes and junctions' because the citadel was abandoned without any specific and clear activity. Thus, 'commercial/ industrial concerns' secondary elements had no effect on the identity; moreover, the functional identity was very weak for the same reason.

The study concluded that there is a remarkable influence of the citadel on Erbil identity, and this influence could be increased through the development of some functional activities inside the abandoned area of the citadel. Accordingly, the study offered strategies to enhance the identity of Erbil through the citadel of Erbil.

\section{Recommendations}

Based on the matrix checklist results, the study gives some recommendations. For example, Development of better facilities to access the citadel area through planning proper corridors and pathways to connect inside of the citadel to outside without affecting the historical value of the place. With the same philosophy, development of the specific activities inside the citadel to increase functional identity. This is done through some strategies like dissembled architectural design strategies, adaptive re-use, to prevent the negative impact on the historical and preserved area.

\section{REFERENCES}

[1] Bell, A., and de-Shalit, A. (2011). The Spirit of Cities, Why the Identity of a City Matters in a Global Age. 
Princeton, USA: Princeton University Press)

[2] Uzzell, DL, Pol, E and Badenes, D. (2002). Place identification, social cohesion, and environmental sustainability. Environment and Behavior, 34(1), 26-53. DOI:10.1177/0013916502034001003

[3] Ujang, N. (2012). Place attachment and continuity of urban place identity. Procedia - Social and Behavioral Sciences, 49, 156-167. http://dx.doi.org/10.1016/j.sbspro. 2012.07.014.

[4] Carmona, M., Tiesdell, S., Heath, T., \& Oc, T. (2010). Public places urban spaces: The dimensions of Urban Design. Oxford: Architectural Press, London, UK.

[5] Gonçalves, A. (2012). Urban identity, by Brian Evans, Frank McDonald and David Rudlin. Urban Research \& Practice, 5(1), 180-181. doi:10.1080/17535069.2012.6564 63

[6] UNESCO. (2003). The Convention for the Safeguarding of the Intangible Cultural Heritage. Retrieved from, https://en.unesco.org/.

[7] Ziyaee, M. (2018). Assessment of urban identity through a matrix of cultural landscapes. Cities, 74, 21-31. doi: 10.1016/j.cities.2017.10. 021

[8] Ibrahim, R., Mushatat, S., Abdelmonem, M.G. (2014). Authenticity, Identity And Sustainability In Post-War Iraq: Reshaping The Urban Form Of Erbil City. Journal of Islamic Architecture Volume, 3(2). https://doi.org/10.1886 0/jia.v3i2.2533

[9] Tomlinson, J. (2003). Globalization and Cultural Identity. In D. Held (Ed.), The Global Transformations Reader: An Introduction to the Globalization Debate (pp. 269-277). Cambridge, UK: Polity.

[10] Shawesh, E. (2000). The changing identity of the built environment in Tripoli City, Libya. Ph.D. thesis, University of Newcastle, UK. Retrieved from http://theses.ncl.ac.uk/jspui/handle/10443/300

[11] Greene, S. (1992). City Shape: Communicating and Evaluation of Community Design. APA J., 58(2), 177-189. https://doi.org/10.1080/01944369208975792

[12] Al-Naim, A. (2008). Identity in Transitional Context: Open-ended Local Architecture in Saudi Arabia. Arch netIJAR, Int. J. Archit. Res., 2(2), 125-146. DOI: 10.26687/archnet-ijar.v2i2.237

[13] Devine-Wright, P. (2009). Rethinking NIMBYism: The Role of Place Attachment and Place Identity in Explaining Place-protective Action. J. Community Appl. Soc. Psychol., 19, 426-441. https://doi.org/10.1002/casp.1004

[14] Abdelmonem, M. G. (2012). the Practice of Home in Old Cairo: Towards Socio-Spatial Models of Sustainable Living. TDSR, 23(2), 35-50. DOI: 10.2307/41758894.

[15] Gurel, M. (2007). Domestic Space, Modernity, and Identity: The Apartment in Med $20^{\text {th }}$ Century Turkey. Ph.D. Dissertation, University of Illinois at Urbana-Champaign. Illinois, United States.

[16] Lynch, K. (1982). Good City Form. Cambridge, Massachusetts, United States: MIT Press.
[17] Hauge, A. L. (2007). Identity and Place: A Critical Comparison of Three Identity Theories. Architectural Science Review, 50(1), 44-51. doi:10.3763/asre.2007.5007

[18] Stokols, D. and Shumaker, S. (1981) 'People in place: a transactional view of settings', in J. Harvey (ed.) Cognition, Social Behaviour and the Environment, Hillsdale, NJ: Lawrence Erlbaum (441 - 488).

[19] TWIGGER-ROSS, C. L., \& UZZELL, D. L. (1996). PLACE AND IDENTITY PROCESSES. Journal of Environmental Psychology, 16(3), 205-220. doi:10.1006/jevp.1996.0017

[20] Breakwell, G. (2015). Coping with Threatened Identities. Sussex, United Kingdom: Psychology Press.

[21] Kermani, A., and Alalhhesabi, C. (2016). Development a Model for relation between Heritage and Place Identity. International Journal of Architecture and Environmental Engineering, 10(3), 406-411. doi.org/10.5281/zenodo.1123 697

[22] UNESCO World Heritage Center. (2008). Operational guidelines for the implementation of the world heritage convention. Paris, France: UNESCO.

[23] Sauer, C. (1925). The morphology of landscape. CA, USA: University of California. Retrieved from, file://C:/Users/AL-BARQ/Downloads/Documents/Sauer\% 20-\%20Morphology\%20of\%20landscape.pdf

[24] Cosgrove, D. (1984). Social formation and symbolic landscape. Wisconsin, USA: University of Wisconsin Press.

[25] Jones, M. (2003). The concept of cultural landscape: Discourse and narratives. In H. Palang, \& G. Fry (Eds.). Landscape interfaces Dordrecht, Netherland: Landscape series. Springer. http://dx.doi.org/10.1007/978-94-017-018 9-1_3.

[26] O’Donnell, P. M. (2008, 29 Sept. - 4 Oct.). Urban Cultural Landscapes and the Spirit of Place. In: 16th ICOMOS General Assembly and International Symposium: 'Finding the spirit of place - between the tangible and the intangible', Quebec, Canada.

[27] Brown, D. G. (2001). Characterizing the human imprint on landscapes for ecological assessment. In M. E. Jensen, \& P. S. Bourgeron (Eds.). A guidebook for integrated ecological assessments. New York, USA: Springer. http://dx.doi.org/10.1007/978-1- 4419-8620-7_28.

[28] Vogeler, I. (2010). Critical cultural landscape of North America. Retrieved from http://people.uwec.edu/ivogeler/ CCL-bookchapters-pdf/index.htm

[29] Stephenson, J. (2008). The cultural values model: An integrated approach to values in landscapes. Landscape and Urban Planning, 84(2), 127-139. http://dx.doi.org/10. 1016/j.landurbplan.2007.07.003.

[30] Sonkoly, G. (2017). Vienna and the Vienna memorandum. Historical urban landscape Cham, Switzerland: Springer. h ttp://dx.doi.org/10.1007/978-3-319-49166-0_3.

[31] Mayall, K., \& Hall, G. B. (2005). Landscape Grammar 1: Spatial Grammar Theory and Landscape Planning. Environment and Planning B: Planning and Design, 32(6), 
895-920. http://dx.doi:10.1068/b31175

[32] Hofstede, G. (1997). Cultures and Organizations: Software of the mind. New York, United States: McGraw Hill.

[33] Morris, A. E. J. (1994). History of Urban Form: before the Industrial Revolution. New York, United States: Wiley \& Sons.

[34] Amin, R., and Muhy Al-Din, S.S. (2019). Evaluation of the Sustainable Aspects In Housing Sector To Overcome Housing Stress In Northern Iraq. Journal of Contemporary Urban Affairs, 3(1), 67-81. https://doi.org/10.25034/ijcua.2 018.4684

[35] Yildiz, K. (2004). The Kurds in Iraq the Past, Present and Future. London, England: Pluto Press.

[36] Martin-Caro, J.A., and Paniagua, I. (2015). Erbil Citadel restoration: some thoughts on earth-built constructions exposed to seismic action. WIT Transactions on
The Built Environment, 168, 583-593. http://dx.doi:10.249 5/SD150511

[37] Khoshnaw, R., and Kissfazekas, K. (2018). Urban Form and Sustainability in Historic Cities: A case study of two neighbourhoods in Erbil City, Iraq. Épités Épitészettudomány, 47(2), 1-27. https://doi.org/10.1556/09 6.2018.014

[38] Nooraddin, H. (2012). Architectural Identity in an Era of Change. IISTE, Developing Country Studies, 2(10), 81-96. Retrieved from, https://core.ac.uk/download/pdf/23468089 5.pdf

[39] Spirn, A. W. (1998). The language of landscape. New Haven, USA: Yale University Press. http://dx.doi.org/10.2 307/3985672.

[40] Khalid, N. J. (2014). Urban Heat Island in Erbil City. Master Thesis. Lund University, Lund. Sweden: Lund University. 